
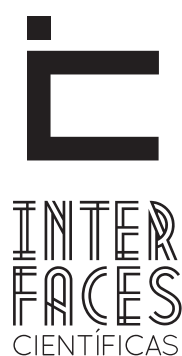

HUMANASE SOCIAIS

ISSN IMPRESSO 2316-3348

E-ISSN 2316-3801

DOI - 10.17564/2316-3801.2017v6n1p101-112

\title{
A DOUTRINA DO MÍNIMO EXISTENCIAL
}

THE DOCTRINE OF EXISTENTIAL MINIMUM

LA DOCTRINA DEL MÍNIMO VITAL

Danielle Sales Echaiz Espinoza ${ }^{1}$

\section{RESUMO}

O recurso ao mínimo existencial tem sido bastante utilizado por juízes e tribunais pátrios para justificarem, especialmente na ausência de políticas públicas, a proteção e a realização de direitos sociais básicos, como saúde, educação e assistência social. Apesar de intensa produção bibliográfica sobre o assunto, muitos questionamentos continuam a ser formulados: o mínimo existencial seria um direito autônomo em face da Constituição brasileira? Qual seria seu conteúdo? Seria uma norma principioló- gica ou uma regra? Com o objetivo de responder a tais indagações, o presente artigo analisa as propostas de três autores brasileiros representativos na abordagem do tema.

\section{PALAVRAS-CHAVE}

Direito Constitucional. Direitos fundamentais. Mínimo Existencial. 


\section{ABSTRACT}

The use of minimum protection has been widely used by judges and patriotic courts to justify, especially in the absence of public policy, protection and fulfillment of basic social rights such as health, education and social assistance. Although in tense bibliographic production on the subject, many questions remain to be formulated: the existential minimum would be an autonomous in face of the Brazilian Constitution? What would it contain? It would be a principle or a rule? In order to answer these questions, this article analyzes proposals for three representative Brazilian authors on the theme approach.

\section{KEYWORDS}

Constitutional Law. Fundamental rights. Minimum protection.

\section{RESUMEN}

El derecho al mínimo vital ha sido ampliamente utilizado por los jueces y tribunales patrios para justificar, sobre todo en la ausencia de políticas públicas, la protección y cumplimiento de los derechos sociales básicos como la salud, la educación y la asistencia social. Aunque intensa producción bibliográfica sobre el tema, siguen siendo muchas preguntas a formularse: el mínimo vital sería un derecho autónomo según la Constitución brasileña?; ¿Cuál sería su contenido?;
¿Sería un principio o una regla? Para responder a estas preguntas, este artículo analiza las propuestas de tres autores brasileños representativos sobre el enfoque temático.

\section{PALABRAS CLAVE}

Derecho Constitucional. Los derechos fundamentales. Mínimo vital. 


\section{INTRODUÇÃ̃O}

Na busca pela efetividade dos direitos fundamentais, a discussão em torno da realização judicial dos direitos sociais a prestação sempre foi muito problemática. Desde muito cedo na teoria constitucional, tais direitos foram rotulados de normas programáticas, destituídos de valor normativo e dependentes inteiramente da vontade do legislador para serem concretizados.

Contudo, o desenvolvimento da teoria da força normativa da constituição e do primado dos direitos fundamentais nos últimos cinquenta anos, impulsionaram a jurisprudência e a doutrina constitucional a criarem instrumentos que viabilizassem o exercício dos direitos sociais quando os poderes responsáveis por garanti-los (Legislador e Executivo) forem omissos.

A doutrina do mínimo existencial pode ser vista como um desses mecanismos. Na tentativa de harmonizar os princípios constitucionais envolvidos, a repartição dos poderes, a reserva orçamentária e os direitos fundamentais, a teoria do mínimo existencial fornece subsídios para autorizar uma interferência judicial em defesa dos direitos sociais, mesmo estes ainda não tendo sido densificados ou garantidos mediante lei e/ou políticas públicas.

Ainda que se reconheça o papel que essa doutrina vem exercendo nos tribunais constitucionais, mormente nos tribunais pátrios, no sentido da efetivação dos direitos sociais - sendo responsável em parte pelo aumento da judicialização em determinadas áreas, como a saúde, muitos questionamentos continuam a ser formulados a seu respeito: quais as prestações que integram o mínimo existencial? 0 mínimo existencial seria um direito autônomo em face da Constituição brasileira? Qual seria seu conteúdo? Seria uma norma principiológica ou uma regra?

Sem nenhuma pretensão de esgotar o tema, especialmente por ter em vista um grande número de juristas nacionais abalizados que têm se debruçado incansavelmente sobre o assunto, o presente trabalho limita-se a examinar a gênese da discussão jurídica em torno do mínimo existencial e seu contexto constitucional, bem como revisitar parcela da doutrina bra- sileira representativa no tema, ressaltando, sobretudo, as diferentes respostas oferecidas às indagações formuladas.

\section{UM CASO PARADIGMÁTICO JULGADO PELO TRIBUNAL CONSITUCIONAL ALEMÃO: A PENSÃO DE ÓRFÃOS COM NECESSIDADES ESPECIAIS}

Segundo registra Sarlet (2007, p. 331), Otto Bachof fora o primeiro jurista, ainda na década de 1950, a defender um direito a condições mínimas de existência decorrente do princípio da dignidade de pessoa humana e do direito à vida. Segundo Bachof, para possibilitar de fato o respeito à dignidade e à integridade da pessoa, o Estado deveria garantir não apenas as esferas de atuação livre do indivíduo, mas as condições materiais para uma existência digna.

Em 1954, o Tribunal Federal Administrativo da Alemanha reconheceu o direito subjetivo do indivíduo desprovido de recursos à assistência social por parte do Estado (SARLET, 2007).

A questão assumiu maior destaque quando, em 1975, uma clássica decisão proferida pelo Tribunal Constitucional Federal alemão reconheceu a assistência social como um dever evidente do Estado Social e como uma garantia de condições mínimas para uma existência humanamente digna. A corte teve que analisar um recurso contra decisão proferida por um tribunal estadual que considerara inconstitucional um dispositivo da legislação previdenciária vigente na época (SCHWABE, 2005).

0 dispositivo impugnado se referia à idade máxima de 25 anos para o recebimento da pensão de órfãos. Segundo o tribunal estadual, no caso de órfãos portadores de alguma deficiência mental ou física o limite etário não deveria prevalecer, já que essas pessoas se encontrariam impossibilitadas de prover seu próprio sustento. Dessa forma, decidiu pela incompatibilidade da regra com o princípio do Estado Social previsto na Lei fundamental.

Ao enfrentar o assunto, o Tribunal Constitucional Federal assentou seu entendimento: 
Com certeza a assistência social aos necessitados faz parte dos deveres mais evidentes de um Estado Social (cf. BVerfGE 5, 85 [198]; 35, 202 [236]). Isto inclui necessariamente a ajuda social ao cidadão que, em razão de deficiência física ou mental, tem seu desenvolvimento pessoal e social impedido, sendo incapaz de prover seu sustento próprio. A sociedade estatal deve, em todo o caso, garantir-lhe as condições mínimas para uma existência humanamente digna, e deve, além disso, esforçar-se para, na medida do possível, incluí-lo na sociedade, estimular seu adequado tratamento pela família ou por terceiro, bem como criar as necessárias instituições de cuidado. Esse dever geral de proteção não pode, naturalmente, terminar em razão de um determinado limite de idade. Ele deve, pelo contrário, corresponder à respectiva necessidade de amparo social. (SCHWABE, 2005, p. 828).

É importante ressaltar que, embora a Corte tenha admitido o direito à assistência social aos órfãos portadores de necessidades especiais como integrante do núcleo de condições materiais mínimas de vida digna, reformulou a decisão do tribunal recorrido, por entender que a norma impugnada não violaria à Constituição, já que o legislador teria competência e liberdade de conformação para utilizar os meios necessários para garantir tal proteção:

\begin{abstract}
Todavia, existem múltiplas possibilidades de se realizar a proteção devida. Encontra-se principalmente na liberdade de conformação do legislador determinar o caminho que se the apresenta como adequado para tanto, especialmente escolhendo entre as diferentes formas de ajuda financeira para o sustento e tratamento de deficientes e consequentemente pré-definido (concretamente) os titulares a tais pretensões. Da mesma forma, ele tem que decidir, desde que não se trate dos caracterizados pressupostos mínimos em qual extensão pode e deve ser garantida ajuda social, considerando-se os recursos disponíveis e outras tarefas estatais de igual importância. (SCHWABE, 2005, p. 828).
\end{abstract}

O Tribunal Constitucional, em deferência à liberdade do legislador, manteve a legislação previdenciária e o limite etário de 25 anos para o recebimento de pensão por parte dos órfãos, ainda que portadores de necessidades especiais.

Em geral, a postura da Corte em decisões seguintes foi também no sentido da auto restrição, ou seja, embora reconhecendo a ofensividade de determinados dispositivos legais ao mínimo existencial, determinou prazo para o legislador corrigir a distorção no âmbito do processo democrático, evitando atuar em seu nome (SARLET, 2012).

\subsection{PROBLEMÁTICA DOS DIREITOS OIGINÁRIOS À PRESTAÇ̃̃ES NA ALEMANHA}

A discussão jurisprudencial e doutrinária a respeito do mínimo existencial na Alemanha justifica-se principalmente pela ausência de previsão constitucional expressa de direitos sociais. Como registra Alexy (2002, p. 421), a Lei Fundamental é muito cautelosa em assegurar explicitamente direitos sociais a prestações, tendo feito em situações muito restritas, como no caso da proteção da maternidade, do casamento e da família.

Dessa forma, discute-se se é possível identificar direitos sociais originários - previstos diretamente na Constituição - como direitos fundamentais implícitos, decorrentes dos princípios da dignidade da pessoa humana e do Estado Social e qual seria sua força vinculante.

Alexy (2002, p. 484) integra a doutrina que defende ser possível extrair da constituição alemã direitos fundamentais sociais implícitos com diferentes graus de vinculação. Para o autor, alguns direitos sociais consistiriam em normas objetivas, vinculantes apenas para o legislador, outros confeririam direitos subjetivos, mas não seriam exigíveis sem atuação legislativa, outros constituiriam direitos subjetivos vinculantes, mas prima facie e, por fim, em grau máximo de vinculação, estariam aqueles direitos subjetivos definitivos.

Segundo Alexy (2002, p. 495), o direito ao mínimo existencial - moradia simples, educação escolar, formação profissional e um nível básico de assistência médica - entraria na categoria de direito subjetivo definitivo vinculante.

Um dos argumentos a favor da proteção de "direitos sociais mínimos" relaciona-se com a necessidade de se garantir liberdade fática ao indivíduo para que ele possa exercer suas liberdades jurídicas. Bens materiais básicos seriam, assim, 
pressupostos para a autodeterminação pessoal. Para pessoas famintas, doentes, maltrapilhas e analfabetas o exercício de liberdades jurídicas, asseguradas constitucionalmente, não faz nenhum sentido, convertem-se em fórmulas vazias. 0 desenvolvimento livre e digno da pessoa humana está associado ao poder de realmente atuar, inexistente na ausência de condições mínimas de sobrevivência (ALEXY, 2002).

Para lidar com as objeções clássicas contra a realização judicial dos direitos sociais - tais como a livre conformação legislativa dentro da separação dos poderes, imprecisão semântica acerca do objeto de tais direitos, falta de parâmetros jurídicos para determinar seu exato conteúdo, efeitos financeiros e seu impacto no limite da previsão orçamentária, Alexy (2002, p. 494) propõe um modelo de direitos fundamentais sociais baseado na teoria dos princípios. Em suas palavras:

Habrá que considerar que uma posición de prestación
jurídica está definitivamente garantizada iusfunda-
mentalmente si (1) la exige mui urgentemente el prin-
cípio de la liberdad fáctica y (2) el principio de la divi-
sión de poderes y el de la democracia (que incluye la
competencia pressupuestaria del parlamento) al igual
que (3) princípios materiales opuestos (especialmente
aquellos que apuntan a la liberdade jurídica de otros)
son afectados em uma medida relativamente reducida
a través de la garantia iusfundamental de la posición
de prestación jurídica y las decisiones del Tribunal
Constitucional que la toman em cuenta. Em todo caso,
estas condiciones estan satisfechas em el caso de lós
derechos fundamentales sociales mínimos, es decir,
por exemplo, a um mínimo vital, a uma vivenda sim-
ple, a la educación escolar, a la formación profesional
y a um nível estándard mínimo de asistencia médica.
(ALEXY, 2002, p. 495).

Assim, para se determinar o que definitivamente o indivíduo tem direito - o mínimo existencial será necessária uma ponderação entre o princípio da liberdade fática, os princípios formais de separação de poderes e reserva orçamentária e ainda com outros princípios materiais e direitos fundamentais envolvidos.

\section{A DOUTRINA BRASILEIRA ACERCA DO MÍNIMO EXISTENCIAL}

Diversamente do contexto alemão, cuja ausência de catálogo de direitos sociais impulsionou doutrina e jurisprudência a desenvolverem um conjunto de direitos sociais mínimos, implícitos e vinculantes, a partir do texto constitucional, no Brasil, a Constituição Federal trouxe um elenco extenso de direitos fundamentais sociais. Qual o propósito, então, de se desenvolver uma doutrina acerca do mínimo existencial em um contexto institucional tão diverso?

A repercussão predominante dessa doutrina no país tem sido sobre a atuação do poder judiciário na implementação de direitos sociais fundamentais. $\mathrm{Na}$ ausência de legislação específica ou de políticas públicas que afetem o exercício de direitos sociais mínimos, os tribunais brasileiros utilizam o recurso ao mínimo existencial para concederem em definitivo prestações na área da saúde e educação, por exemplo.

Contudo, a doutrina brasileira diverge quanto à fundamentação e amplitude do conceito de mínimo existencial, quanto à possibilidade de se estabelecer um conjunto de prestações abstratas mínimas, quanto à existência de um direito fundamental autônomo ao mínimo existencial e ainda quanto à sua estrutura, se princípio ou regra. Para demonstrar tais divergências, em seguida, será feita uma análise do posicionamento de três autores representativos no estudo da matéria.

\subsection{RICARDO LOBO TORRES}

Data de 1989 o primeiro escrito de Torres sobre 'mínimo existencial e direitos fundametais', que pode ser considerado um marco para o estudo do tema no país ${ }^{1}$. Nesse trabalho, o autor defende o direito às condições mínimas de existência humana digna fundamentado na ideia de pressuposto inicial da liberdade. Sem possibilidade de sobrevivência ou em estado de pobreza absoluta não existem condições de

1 No mesmo sentido, Sarlet (2007, p. 303). 
exercício da liberdade. Também decorre do princípio da igualdade (proteção contra pobreza absoluta), do respeito à dignidade da pessoa humana e da cláusula do Estado Social (TORRES, 1989).

O direito ao mínimo existencial não tem expressa previsão constitucional, nem conteúdo específico já que poderia abranger qualquer direito essencial à sobrevivência digna ainda que não seja fundamental, como saúde e educação. Também não é quantificável já que é um direito mais associado à qualidade de vida do que a um número determinado de bens ou prestações dos quais o indivíduo pode usufruir (TORRES, 1989).

É importante registrar que, para Torres (1989, p. 34), o mínimo existencial não se confunde com os direitos sociais e econômicos que estão atrelados à ideia de promoção de justiça social cuja eficácia depende inteiramente do legislador e das contingências econômicas do país. Os direitos sociais estão situados na esfera do status positivus socialis do indivíduo, configurando o máximo em prestações de bem estar que se pode exigir do Estado, determinadas por escolhas políticas e limitadas pelas possibilidades financeiras (TORRES, 2001). Ao contrário, o mínimo existencial é condição de liberdade, configura proteção do indivíduo contra ingerência indevida do legislador em ações e bens que possibilitem a sobrevivência digna (status negativus), bem como consiste no direito a prestações estatais básicas para o alcance dessa sobrevivência digna (status positivus libertatis) (TORRES, 1989).

Nesse ponto, ressaltam-se os dois elementos presentes da doutrina do mínimo existencial em Torres: um aspecto negativo de direito de defesa e um aspecto positivo de direito à prestação. 0 status negativus do mínimo existencial configura um poder de autodeterminação da pessoa que deve ser exercido sem o constrangimento por parte do Estado, impedindo-o de interferir por meio da tributação em bens e atividades essenciais à subsistência do cidadão (TORRES, 1989).

Nesse contexto, situam-se o elenco de imunidades tributárias constitucionais explícitas, tais como a assistência jurídica integral e gratuita àqueles desprovidos de recursos, gratuidade das ações de habeas corpus, ação popular e habeas data, gratuidade para os pobres na forma da lei de certidões de nascimento e óbito, imunidade de impostos das instituições de educação e de assistência social sem fins lucrativos, não incidência de imposto de renda sobre rendimentos provenientes de aposentadoria e pensão de pessoas com mais de 65 anos cuja renda total seja, exclusivamente, de rendimentos do trabalho, imunidade de imposto territorial rural sobre pequenas glebas rurais etc. (TORRES, 1989).

Ainda dentro dessa perspectiva negativa, encontram-se as imunidades revestidas sobre a denominação de isenções e não incidência tributária, tais como a faixa de rendimentos isentos do pagamento de imposto de renda (IR), a isenção do IR sobre quantias necessárias à subsistência dos dependentes do declarante, deduções do IR a pagar sobre despesas médico-hospitalares, educação e gastos com o sustento de dependentes e isenção de impostos indiretos sobre produtos essenciais de consumo (da cesta básica, por exemplo).

Já o status positivus libertatis do mínimo existencial "postula a entrega de prestações de assistência social aos pobres, de auxílios financeiros a entidades filantrópicas e de bens públicos (roupas, remédios, alimentos etc.) à população carente" (TORRES, 2003, p. 15). Tais prestações, contudo, só podem ser exigidas por meios judiciais quando "o sistema previdenciário público ou privado falhar em sua missão e o indivíduo não possuir os meios indispensáveis à sobrevivência." (TORRES, 1989, p. 40).

Um ponto a ser ressaltado ainda na doutrina do autor é que as prestações positivas do mínimo existencial não se encontram à disposição dos poderes executivo e legislativo, nem estão submetidos à reserva do possível (ao contrário dos direitos sociais e econômicos). Isso significa que:

Em outras palavras, o Judiciário pode determinar a entrega das prestações positivas, eis que tais direitos fundamentais não se encontram sob a discricionariedade a Administração ou do Legislativo, mas se compreendem nas garantias institucionais da liberdade, na estrutura dos serviços públicos, essenciais e na organização de estabelecimentos públicos (hospitais, clínicas, escolas primárias etc.). (TORRES, 2013, p. 74). 
Não se pode concluir, contudo, que tal tese possa referendar a excessiva judicialização em algumas matérias como o exemplo da saúde. Segundo Torres (2013), nesse caso, a pretensão a ser deduzida em juízo pelo cidadão deverá ser à implementação da política pública por parte do Estado e não à entrega individual de bens públicos. Como pontua:

Nesses casos, a política pública se torna indispensável, e a decisão judicial deve obrigar à implementação da policy pelos poderes políticos (Legislador e Executivo). A insistência do Judiciário brasileiro no adjudicar bens públicos individualizados (ex. remédios), ao revés de determinar a implementação da polítia pública adequada, tem levado à predação da renda pública pelas elites, a exemplo do que acontece em outros países. (TORRES, 2013, p. 75).

\subsection{ANA PAULA BARCELOS}

Para Barcellos, a ideia de mínimo existencial está essencialmente ligada à noção de dignidade da pessoa humana e ao seu aspecto sociocultural, na medida em que este exige o desenvolvimento de direitos sociais, econômicos e culturais para a plena realização da pessoa. 0 mínimo existencial, na visão da autora, "nada mais é que um conjunto formado por uma seleção desses direitos, tendo em vista principalmente sua essencialidade, dentre outros critérios" (BARCELLOS, 2002 p. 14).

Diversamente de Torres, para a autora, o mínimo existencial não configura um direito autônomo, mas representa um subconjunto de direitos sociais, econômicos e culturais menor, cujo conteúdo por ser mínimo (e ter menor impacto financeiro), pode ser plenamente exigível através do judiciário (BARCELLOS, 2002).

Sublinha que o mínimo existencial é o núcleo irredutível da dignidade da pessoa humana e por isso mesmo consiste em uma regra no sentido alexyano, cujo cumprimento não comporta ponderação com reserva do possível, orçamento e separação dos poderes.

Segundo Barcellos (2002, p. 45), o conteúdo mínimo vital já estaria determinado pela Constituição sendo necessário para identificá-lo a simples interpretação sistemática. Nesse sentido, afirma:
[...] o mínimo existencial que ora se concebe é composto de quatro elementos, três materiais e um instrumental, a saber: a educação fundamental, a saúde básica, a assistência aos desamparados e o acesso à justiça. Repita-se, ainda uma vez, que esses quatro pontos correspondem ao núcleo da dignidade da pessoa humana a que se reconhece eficácia jurídica positiva e, a fortiori, o status de direitos subjetivo exigível diante do poder judiciário. (BARCELLOS, 2002, p. 259).

Assim, desenvolve a autora um conteúdo abstrato do mínimo existencial e o situa como uma regra, ou seja, um dever definitivo estatal a cujo cumprimento não se pode opor nenhum outro princípio constitucional formal ou material.

\subsection{INGO WOLFGANG SARLET}

Segundo Sarlet (2012, p. 251), é importante diferenciar mínimo existencial de mínimo vital. Este último está associado à garantia de existência física do indivíduo, corolário do seu direito à vida - alimentação, atendimento médico de urgência, assistência social - contudo, o mínimo existencial é mais abrangente, já que, além disso, também assegura um padrão de inclusão social, cultural e político mínimo (decorrente do Estado Social), como o direito à educação.

No entanto, destaca que não há como se estabelecer abstratamente critérios capazes de aferir um padrão mínimo de existência digna. Em sua concepção, "todas as prestações indispensáveis à promoção, proteção e fruição de uma vida digna (que podem variar de acordo com as circunstâncias) necessariamente compõem o mínimo existencial" (SARLET, 2010, p. 346).

O conteúdo do mínimo existencial deve permanece em aberto, especialmente tendo em vista sua correlação com necessidades sociais concretas de uma determinada época e de uma comunidade específica. “Nesse sentido, é possível falar-se até mesmo em mínimo existencial ecológico, no qual se inserem prestações básicas como o direito ao saneamento básico e à água potável” (SARLET, 2010, p. 29-33).

Sarlet defende que o direito ao mínimo existencial é um direito fundamental autônomo - que não se con- 
funde com o núcleo essencial dos direitos sociais ${ }^{2}$ com caráter subsidiário, ou seja, sua função precípua é servir de parâmetro de interpretação do conteúdo e eficácia dos direitos sociais, justificando, inclusive, a concessão de determinadas prestações via judicial mesmo contra a vontade dos poderes executivo e legislativo (SARLET, 2012). Para isso, no entanto, será sempre necessária uma:

[...] contextualização em cada oportunidade que se pretender extrair alguma consequência jurídica concreta em termos de proteção negativa ou positiva dos direitos sociais e do seu conteúdo essencial, seja ele, ou não, diretamente vinculado a alguma exigência concreta da dignidade da pessoa humana. (SARLET, 2010, p. 257).

Na esteira de Torres e Barcellos, o autor admite que o mínimo existencial consista em um direito subjetivo definitivo, que afasta as considerações de reserva do possível e a liberdade de conformação do legislador, autorizando a tutela judicial dos direitos envolvidos.

Apesar desse entendimento, reconhece que os excessivos custos financeiros até mesmo para assegurar direitos sociais mínimos e a exigência de políticas públicas universais impõem a necessidade de, à luz do caso concreto, discutir uma série de questões tendo em vista a definir a prestação a ser concedida a determinado indivíduo pelo Judiciário (SARLET, 2013).

Nesse sentido, em relação à tutela judicial do direito à saúde, Sarlet aponta um conjunto de condicionamentos que deveriam orientar e limitar a atuação do judiciário, tais como: inexistência de tratamento alternativo eficiente, indispensabilidade do tratamento, proteção às pessoas efetivamente carentes de recursos, preferência em tutelas de urgência, eficiência e segurança do tratamento pleiteado, vedação de autorização de tratamentos experimentais, inexistência de

20 núcleo essencial dos direitos fundamentais consiste em um conteúdo irredutível, impassível de intervenção do Estado e da Sociedade por meio de ponderação. Como sublinha o autor, nem todos os direitos sociais são direitos fundamentais materiais, ou seja, nem todos decorrem implicitamente do princípio da dignidade da pessoa humana. Nesse sentido, não seria correto afirmar que o núcleo essencial dos direitos sociais se confunde com mínimo existencial, pois este só se manifesta em direitos diretamente decorrentes da promoção, proteção e realização da pessoa humana (SARLET, 2012, p. 255-257) obrigação genérica ao fornecimento de todo medicamento ou tratamento novo etc. (SARLET, 2013).

Todas essas condicionantes parecem, portanto, indicar que o mínimo existencial a ser protegido concretamente só pode ser determinado após uma ponderação com demais bens, direitos e princípios envolvidos.

\section{MIIIIMO EXISTENCIAL EM ABSTRATO E EM CONCRETO}

Uma teoria constitucionalmente adequada acerca do mínimo existencial no Brasil deve levar em consideração tanto a forma de positivação dos direitos sociais na Constituição de 1988 como o contexto (sociopolítico) brasileiro de baixa efetividade dos direitos fundamentais a prestação e de inércia crônica dos poderes competentes para implementarem as políticas públicas constitucionais ${ }^{3}$.

Nesse sentido, a doutrina do mínimo existencial no país não se desenvolve com o objetivo de identificar quais os direitos sociais a prestações fáticas que seriam fundamentais e que poderiam ser exigidos a partir do próprio texto constitucional (direitos sociais originários), independente da atuação do legislador, como na Alemanha ou em Portugal, por exemplo4 ${ }^{4}$. A Constituição Federal foi pródiga em assentar expressamente um extenso rol de direitos sociais a prestação e indistintamente atribuiu a todos os direitos fundamentais aplicabilidade imediata e plena exigibilidade, o que de fato redireciona a doutrina do mínimo existencial no país para a eficácia desses direitos.

Não se pode deixar de reconhecer, ao contrário de Torres, a intrínseca relação entre mínimo existencial e direito social. Todas as prestações básicas consideradas

3 A respeito da teoria constitucionalmente adequada, conforme Echaiz-Espinoza (2009), defendemos a ideia de que uma teoria constitucional adequada é aquela elaborada a partir da Constituição positiva, com seus princípios (e regras) explícitos e implícitos. Também sublinhamos a necessidade de se levar em conta a realidade sociopolítica brasileira que muito contribui para o contexto de inefetividade da Constituição e dos direitos fundamentais.

4 Consultar a respeito da problemática da eficácia de tais direitos na Constituição Portuguesa em Vieira de Andrade (2001). 
como condições mínimas de existência digna incluem direitos sociais - saúde básica, educação escolar, assistência social, alimentação, moradia aos indigentes, assistência jurídica. Um direito fundamental autônomo ao mínimo existencial só faz sentido se o mesmo mantiver seu caráter subsidiário, como percebe Sarlet, para auxiliar o legislador a respeitar uma esfera mínima de liberdade geral do indivíduo - imune à constrição tributária do Estado -, bem como servir de parâmetro para justificar a tutela judicial de prestações sociais básicas se e quando os poderes Legislativo e Executivo forem omissos, total ou parcialmente.

Um dos pontos problemáticos nessa doutrina é estabelecer qual a prestação básica devida numa situação concreta. Segundo a proposta de Barcellos, os quatro elementos do mínimo existencial - educação fundamental, saúde básica, assistência social e assistência jurídica - constituem deveres estatais definitivos (regras), plenamente justiciáveis, aos quais não se podem opor nenhum outro princípio.

Contudo, algumas perguntam continuam sem resposta: o que são prestações básicas na área da saúde e assistência, por exemplo? É saúde preventiva ou curativa? Qual tratamento, qual medicamento, qual cirurgia? Qual o benefício? Quem são os necessitados? Se bastar a referência ao direito à saúde básica e a constatação da ausência de determinada política pública para se pleitear no Judiciário toda e qualquer prestação nessa área, não estaríamos diante de um máximo social e não de um mínimo? Em se tratando de máximos, o Judiciário estaria autorizado a atuar?

Tais questionamentos encaminham a temática do mínimo existencial para a consideração de dois aspectos. 0 primeiro deles diz respeito ao fato de que, mesmo em se tratando de direitos sociais mínimos como aqueles assinalados, há um custo muito alto para o Estado que deverá ser suportado de acordo com escolhas técnicas e financeiras, levando-se em consideração diversos outros bens e direitos envolvidos (ALEXY, 2002). Nesse sentido, a prestação devida via judicial só poderá ser fixada após uma ponderação entre a liberdade fática, os princípios formais e materiais opostos tomados em seu conjunto.
Como afirma Alexy (2002, p. 494), “la cuestión acerca de cuáles son los derechos definitivamente es una cuestión de la ponderación de princípios”. Frisa ainda que as ponderações necessárias relativas à exigibilidade dos direitos sociais, segundo o modelo de princípios, podem, sob determinadas circunstâncias, conduzir a direitos definitivos diferentes.

Com isso, questiona-se a posição de Barcellos quanto à inoponibilidade do mínimo existencial estabelecido em abstrato. Fixar um conteúdo abstrato para direitos tão complexos como aqueles integrantes do mínimo existencial só poderia funcionar bem se tal conteúdo fosse tipo por princípio e não por regra.

Dessa forma, pode-se falar em mínimo existencial abstrato, enquanto princípio - um direito às condições mínimas para uma existência digna relacionadas com saúde básica, educação escolar, assistência social e assistência jurídica às pessoas carentes de recursos e moradia aos indigentes - e mínimo existencial concreto - a prestação específica a ser concedida pelo Estado, regra ou dever definitivo estatal, estabelecida pelo Legislador ou pela tutela jurisdicional, em caráter subsidiário após uma ponderação.

Há que se reconhecer, na esteira de Sarlet, a abertura material do conteúdo do direito ao mínimo existencial, enquanto princípio, que pode variar de acordo com as necessidades de uma época e/ou de uma comunidade. Contudo, questiona-se se um conceito de mínimo existencial como aquele referido a "todas as prestações indispensáveis à promoção, proteção e fruição de uma vida digna" (SARLET, 2004, p. 346) não acabaria por maximizar os direitos mínimos de condição de liberdade em direitos máximos de bem estar social pleno, como sublinha Alexy (2002, p. 485):

\footnotetext{
Un programa minimalista apunta a assegurarle 'al individuo el domínio de um espacio vital y um status social mínimos', es decir, aquello que fue llamado de 'derechos mínimos' y derechos sociales 'pequeňos'. Em cambio, estamos em frente a um contenido maximalista cuando se habla de uma 'realización plena' de lós derechos fundamentales o cuando el derecho a la educación es caracterizado como 'derecho a la emancipación cultural-intelectual a la individualidad, a la autonomia, a la madurez político-social'.
} 
Nesse aspecto, a discussão em torno do mínimo existencial seria deslocada para outro plano, aquele acerca da plena realização dos direitos sociais decorrente da dignidade a pessoa humana.

\section{CONCLUSÃO}

A doutrina do mínimo existencial se desenvolve com o objetivo de identificar um conjunto de direitos sociais mínimos destinados a assegurar as condições indispensáveis à subsistência da pessoa e ao exercício de suas liberdades.

No contexto brasileiro, a defesa do mínimo existencial vem reforçar a proteção, promoção e eficácia de direitos fundamentais sociais básicos que muitas vezes são negligenciados pelo Legislador e pelo Executivo.

Identificado por alguns autores nacionais como direito fundamental implícito decorrente da dignidade da pessoa humana e da liberdade fática, teria a função subsidiária de servir como parâmetro de interpretação e aplicação dos direitos sociais. Pode configurar tanto um de direito de defesa - esfera de ação livre do indivíduo que impede o Estado de tributar situações ou bens necessários à sua sobrevivência digna - como um direito a prestações estatais básicas - como, por exemplo, na área da saúde preventiva, curativa (de urgência e emergência), ensino escolar fundamental, assistência social, assistência jurídica gratuita aos desprovidos de recursos e moradia simples a sem-teto ou a indigentes.

Por sua relação com as necessidades concretas de uma comunidade em determinada época, o conteúdo do mínimo existencial não deve se restringir a fixação de um catálogo rígido de prestações, razão pela qual se pode falar atualmente, inclusive, em mínimo existencial ecológico, para abranger o direito à água potável e ao saneamento básico.

A discussão em torno da determinação da prestação devida, especialmente no âmbito do Judiciário, não poderá dispensar a teoria dos princípios e seu modelo subjacente da ponderação. 0 que, em caráter excepcional poderá ser concedido pelo Judiciário, só pode ser determinado após uma ponderação entre a importância da liberdade fática, a afetação dos princípios formais de competência legislativa e reserva orçamentária e o grau de restrição de outros bens e direitos materiais envolvidos. Nesse sentido, seria possível se falar em mínimo existencial em abstrato (princípio) e mínimo existencial em concreto (regra).

Em que pese o esforço da doutrina brasileira em assentar os contornos jurídicos do mínimo existencial, ainda se faz necessário o enfrentamento devido da matéria pelo Supremo Tribunal Federal, especialmente quando se tem em vista evitar o recurso ao mínimo existencial como simples apelo retórico de decisão.

\section{REFERÊNCIAS}

\section{ALEXY, Robert. Teoría de los derechos}

fundamentales. Centro de Estudios Políticos e Constitucionales: Madri, 2002.

BARCELLOS, Ana Paula de. O Mínimo Existencial e Algumas fundamentações Jonh Rawls, Michael Walzer e Robert Alexy. In: TORRES, Ricardo Lobo (Org.). Legitimação pelos direitos humanos. Rio de Janeiro: Renovar, 2002.

\section{BARCELLOS, Ana Paula de. A eficácia jurídica dos} princípios constitucionais: o princípio da dignidade da pessoa humana. Rio de Janeiro: Renovar, 2002.

\section{ECHAIZ-ESPINOZA, Danielle Sales. Entre}

substancialismo e procedimentalismo: elementos para uma teoria constitucional brasileira adequada. Maceió: Edufal, 2009.

\section{SARLET, Ingo Wolfgang. A eficácia dos direitos}

fundamentais. 4.ed. Rev. e Atual. Porto Alegre: Livraria do advogado, 2004.

SARLET, Ingo Wolfgang. Mínimo existencial e Direito privado: apontamentos sobre algumas dimensões da possível eficácia dos direitos fundamentais sociais 
no âmbito das relações jurídico-privadas. SOUZA NETO, Cláudio Pereira; SARMENTO, Daniel (Org.). In: A constitucionalização dos direitos: fundamentos teóricos e aplicações específicas. Rio de Janeiro: Lumen Juris, 2007.

SARLET, Ingo Wolfgang. Estado socioambiental e mínimo existencial (ecológico) algumas aproximações. In: SARLET, Ingo Wolfgang (Org.). Estado socioambiental e direitos fundamentais. Porto Alegre: Livraria do Advogado, 2010.

SARLET, Ingo Wolfgang. Dignidade (da pessoa) humana, mínimo existencial e justiça constitucional: algumas aproximações e desafios. In: LEITE, George Salomão; SARLET, Ingo Wolfgang (Org.). Jurisdição constitucional, democracia e direitos fundamentais. Salvador: Juspodivm, 2012.

SARLET, Ingo Wolfgang. Reserva do possível, mínimo existencial e direito à saúde: algumas aproximações In: SARLET, Ingo Wolfgang; TIMM, Luciano Benetti (Org.). Direitos fundamentais, orçamento e reserva do possivel. 2.ed. Rev. e Atual. Salvador: Juspodivm, 2013.

\section{SCHWABE, Jürgen. Cinquenta anos de} jurisprudência do tribunal constitucional federal alemão. MARTINS, Leonardo (Org.). Montevideu: Fundación Konrad Adenauer Stiftung, 2005.
TORRES, Ricardo Lobo. O mínimo existencial e os direitos fundamentais. Revista de Direito

Administrativo, Rio de Janeiro, n.177, jul/set. 1989.

TORRES, Ricardo Lobo. A cidadania multidimensional na era dos direitos. In: TORRES, Ricardo Lobo (Org.). Teoria dos direitos fundamentais. 2.ed, revista e atualizada. Rio de Janeiro: Renovar, 2001.

TORRES, Ricardo Lobo. A metamorfose do direitos sociais em mínimo existencial. In: SARLET, Ingo Wolfgang (Org.). Direitos fundamentais sociais: estudos de direitos constitucional, internacional e comparado. Rio de Janeiro: Renovar, 2003.

TORRES, Ricardo Lobo. O mínimo existencial, os direitos sociais e os desafios de natureza orçamentária. In: SARLET, Ingo Wolfgang e TIMM, Luciano Benetti (Org.). Direitos fundamentais, orçamento e reserva do possível. 2.ed. Rev.e Amp. $2^{\mathrm{a}}$ tiragem. Porto Alegre: Livraria do Advogado, 2013.

\section{VIEIRA DE ANDRADE, José Carlos. Os direitos} fundamentais na constituição portuguesa de 1976. 2.ed. Coimbra: Almedina, 2001. p.384 e ss. 
